\title{
La imagen del destino y el comportamiento de compra del turista
}

DOI: $10.22403 /$ UQROOMX/TYP03/07

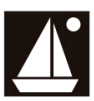

Roberto C. Pons García* Leidy Morales Morales Yelenys Díaz González

Resumen

De todas las decisiones que tiene que tomar el turista potencial, la elección del destino vacacional es la más importante. Sin embargo, existen divergencias entre los investigadores a la hora de identificar y señalar los diferentes elementos que intervienen en el proceso de decisión de un destino turístico. Este trabajo propone que en la mayoría de los casos la imagen del destino es el factor determinante de esa decisión. Como la elección de unas vacaciones no puede explicarse exclusivamente en términos del entorno objetivo, la percepción y actitud del turista potencial sobre el producto turístico se convierte en un elemento central. El objetivo de este trabajo es conocer la influencia de la imagen del destino turístico (percepción-actitud) en el comportamiento de compra del turista y, a partir de ello, desarrollar un modelo de elección del destino que tome en cuenta esa influencia, así como los demás elementos o aspectos que intervienen en el proceso de decisión turística.

Palabras | Comportamiento del turista, elección de destinos, imagen, CLAVE marketing de destinos.

*Universidad Central de Las Villas / rpons@fce.uclv.edu.cu

**Universidad Central de Las Villas / leidymm@fce.uclv.edu.cu

*** Universidad Central de Las Villas / yelenysdg@ fce.uclv.edu.cu 


\section{Introducción}

La importancia del estudio de la imagen del destino turístico reside en saber si determinadas ideas, conocimientos, creencias, sentimientos, entre otros, acerca de un destino influyen en las conductas de viaje. Según numerosos estudios (Crompton et al., 1999; Uysal et al., 2000) el atractivo de un destino es el reflejo de la imagen que se tenga de él, es decir, la percepción de la capacidad que tenga un destino para satisfacer las necesidades y deseos de ocio del turista. Por ello, está aceptado que cuanto más confíe el potencial turista en que un destino satisfará sus necesidades de ocio, mayor será la probabilidad de ser elegido.

Si se acepta que la imagen de un destino es resultado de la influencia del marketing del destino en general, de comunicaciones, experiencias y activos intangibles en relación con él y su oferta turística en particular, dada la compleja naturaleza del producto turístico (destino en sí), se debe reconocer que el componente perceptual / cognitivo es necesario para definir cualquier aproximación científicamente correcta al concepto de imagen. Además, siguiendo a Baloglu y McCleary (I999), se ha reconocido la necesidad de tomar en cuenta el componente afectivo. Por tanto, se debe considerar la imagen de un destino turístico como resultado de las percepciones y actitudes que se tengan de él.

Ahora bien, en el sector turístico, donde existe actualmente una intensa competencia y las nuevas prestaciones han de introducirse en los mercados con garantía y prestigio, es absurdo gastar o hacer un esfuerzo comercial si la demanda se proyecta en campos de decisión distintos de los de la oferta o viceversa.

Sin embargo, existen divergencias entre los investigadores a la hora de identificar y señalar los diferentes elementos que intervienen en el proceso de decisión turística. En la mayoría de los casos, como se verá en este trabajo, la imagen del destino se señala como el factor determinante de la decisión. De hecho, como la elección de unas vacaciones no puede explicarse exclusivamente en términos del entorno objetivo, se convierte la percepción y actitud del turista potencial sobre el producto turístico en un elemento central a considerar. De todas las decisiones que ha de afrontar el potencial turista, la elección del destino vacacional es la más importante; además, el destino es el elemento más importante del "sistema turístico". 
El objetivo de este trabajo, por tanto, será conocer la influencia de la imagen del destino turístico (percepción-actitud) en la decisión de compra del turista y, a partir de ello, desarrollar un modelo de elección del destino que tome en cuenta dicha influencia, así como los demás elementos o aspectos que intervienen en el proceso de decisión turística.

Para ello, fue necesario partir del conocimiento de los aspectos generales del comportamiento del consumidor y una primera aproximación al lugar y papel de la imagen (percepción-actitud) en el comportamiento del consumidor en el campo turístico. Con vistas al desarrollo de un modelo de elección del destino turístico, necesariamente se hace una breve referencia a la teoría de las necesidades, deseos y motivaciones turísticas en general. Posteriormente, se tratará de demostrar el rol de la percepción y las actitudes (imagen) en el proceso de elección de un destino turístico. Previo al desarrollo del modelo de elección de destinos turísticos se consideró necesario analizar la estructura del proceso de toma de decisión en algunos de los más importantes modelos de comportamiento de compra del turista así como sus límites descriptivos.

\section{Una aproximación al papel de la imagen en los modelos de comportamiento del consumidor turístico}

El marketing turístico debe ser capaz de comprender la demanda del futuro, conocer cada tipo de turista, cómo dispondrá de su tiempo libre, cuánto tiempo dedicará a las vacaciones, cómo las distribuirá a lo largo del año y, sobre todo, cómo efectuará la selección de los lugares de vacaciones.

Los modelos de comportamiento del consumidor están fundamentalmente relacionados con la identificación de la función de su preferencia y su traslación a un modelo de elección. El objetivo de este tipo de modelos es tratar de explicar todos los procesos internos y externos que transforman los estímulos en decisiones de compra o no compra, y poner al descubierto todos los mecanismos que influyen en el proceso de compra (Kotler, 1983, 1997). Entre los modelos más conocidos de comportamiento del consumidor en general, figuran los modelos de Nicosia (1966), Howard y Sheth (1969) y Engel, Kollat y Blackwell (1968) similar al de Engel, Blackwell y Miniard (1986).

En el campo turístico la actividad investigadora ha dado nacimiento a distintos modelos, se retienen entre otros los modelos de Schmoll (1977), 
Mathieson y Wall (1982), Moutinho (1987), Woodside y Lysonski (1989), Um y Crompton (1990), Goodall (1992), Mansfeld (1992) y, finalmente, Sönmez y Graefe (1998). Así pues, mientras los modelos generales explican el comportamiento de los consumidores, en la estructura de los modelos de comportamiento del turista, de forma muy destacada se puede distinguir una lógica secuencial en la que la motivación, la percepción y las actitudes dan lugar a mecanismos de decisión que desembocan en la elección de un destino en particular.

Según Middleton (1988), Holloway y Robinson (1995), Kotler et al. (1997), Lumsdom (1997) y Sessa (1989), entre otros autores, debido a la intangibilidad del producto turístico, su heterogeneidad, agregabilidad y la distancia física entre la oferta y la demanda, lo más importante que los destinos turísticos pueden comercializar son imágenes, que se han de transmitir al público por medio de acciones de comunicación; $y$, por tanto, tomar decisiones de comercialización exige conocer las bases del comportamiento humano que influyen en la decisión de comprar, como se ha comentado ya en la introducción. Por consiguiente, se analizará el papel e importancia de la motivación, la percepción y las actitudes en los modelos de comportamiento del turista. Por ello, es imprescindible conocer el papel y lugar que ocupa la imagen en el comportamiento de compra del potencial turista y que le puede llevar o no a la elección de un destino en particular.

A pesar de no existir un consenso en cuanto a la definición precisa de imagen de un destino turístico, se asume que es el resultado de la percepción y actitud del cliente con respecto al destino o destinos turísticos potenciales en un momento determinado (la percepción y actitud hacia el producto turístico). La percepción y actitud que los clientes tienen (imagen) debe deducirse de la conceptualización que hayan hecho del destino. Esto se plantea, sobre todo, si se parte del hecho de que los conceptos de percepción y actitud toman en cuenta (o abarcan) aspectos o conceptos como las ideas, creencias, sentimientos, preferencias, impresiones, valores, prejuicios, conocimientos y estereotipos, comúnmente mencionados en las definiciones de imagen de un destino turístico.

Los diferentes intentos de conceptualización de la imagen del destino tienen como aspectos centrales, por tanto, las características de la oferta turística (producto turístico) y la percepción y actitud (relativas al cliente/ turista). Es decir, el destino turístico se constituye como un "producto turístico 
en si'" y su imagen refleja las actitudes globales del cliente/turista basadas en la percepción de las características o atributos del destino. Mientras que la imagen es un análisis de la percepción sobre un producto/marca/destino, superior a la descripción individual de cada uno de sus atributos, la actitud hace alusión a la relación percepción-preferencia.

Inicialmente, se hace una breve referencia a la teoría de las necesidades, deseos y motivaciones turísticas que por lo general en casi todos los modelos de comportamiento del consumidor -ya sea en los desarrollados en el campo turístico-, se encuentran en el principio de la secuencia que conduce a la compra o elección de un destino turístico o cualquier producto en particular.

Para cualquier individuo la decisión de viajar está basada en unas necesidades y deseos. La noción de necesidad está muy unida al sentimiento de falta de "algo", que el individuo hecha de menos en su esquema mental de referencia (Maslow, 1970); sin embargo, hay que explicarla como proveniente de un estado que no está equilibrado. El ser humano tratará de equilibrarse realizando las acciones pertinentes, empezando por generar deseos que intentará hacer efectivos.

Las necesidades pueden cubrirse de diversas formas; a estas formas que cada persona escoge para cubrir su necesidad se les llama deseos. Es evidente que las necesidades son el origen de los impulsos de compra; sin embargo, cada individuo se comporta de una manera distinta cuando pone en práctica los diversos mecanismos que posee y puede poner en juego en un momento dado para satisfacer aquéllas.Ahora bien, las necesidades y deseos determinan las motivaciones, es decir, definitivas y positivas inclinaciones a hacer algo.

La teoría básica de la motivación la describe como un proceso dinámico de factores psicológicos internos (necesidades, deseos y metas) que generan un nivel incómodo de tensión al interior de las mentes y cuerpos de los individuos. Estas necesidades internas y la tensión resultante guían las acciones diseñadas para liberar la tensión, siendo ésta el medio para satisfacer las necesidades.

Para Crompton (2000), la motivación es una acción o fenómeno que incide sobre el individuo y que produce o intenta producir una respuesta, siendo una variable muy importante en las teorías de la conducta (mueve a actuar). La motivación es un proceso dinámico, sinónimo de impulsar a la acción y de activar el comportamiento. Se puede decir que una persona está más o menos motivada según la energía o el esfuerzo que está dispuesta a poner en un determinado comportamiento. En resumen, por motivación se puede entender 
la razón que impulsa al turista a realizar el viaje turístico. Lo fundamental para entender la motivación turística es ver al viaje vacacional como un satisfactor de necesidades y deseos.

Está generalmente aceptado que en las motivaciones para un viaje de ocio incluyen factores que "empujan" (push factors) relacionados con el entorno doméstico; como el descanso del trabajo, salida de la rutina, o una tregua para el aburrimiento de todos los días;y factores que "tiran" (pull factors) relacionados con los estímulos de nuevos lugares y las atracciones de los destinos.

El análisis de las motivaciones (generadoras de todo el proceso o parte) puede revelar la vía a través de la cual la gente se plantea sus objetivos para la elección de sus destinos, y cómo estos objetivos son reflejados tanto en la elección como en su conducta de viaje. Este análisis de las motivaciones permite un mejor entendimiento de las expectativas reales, necesidades y objetivos/ metas de los turistas. Este aspecto es esencial para la creación de "productos vacacionales" a medida, diseñados para satisfacer las necesidades y expectativas de los turistas. No obstante, de acuerdo con diferentes autores, las motivaciones turísticas presentan limitaciones con vistas a predecir el comportamiento del turista. En primer lugar, la lista de factores o motivaciones de viaje que se ha utilizado en el campo del turismo no es un reflejo consistente del espectro que configura los determinantes principales de la conducta de viaje. Otro aspecto es la compleja naturaleza de la motivación turística.Algunos investigadores sugieren que la conducta de viaje está controlada en el tiempo por "motivaciones intrínsecas"; por tanto, esta característica de la motivación es apenas medible por positivos métodos deterministas.Varios estudios recientes han aceptado por un lado que el viaje turístico es el resultado de varias motivaciones simultáneas y por otro, que su importancia relativa difiere para cada potencial turista; para ello, en sus estudios han usado una lista de motivaciones "principales" (asumen que existe solamente una motivación principal y así sucesivamente) a falta de una teoría que pruebe el tema multidimensional determinante (multimotivacional).

Como se ha analizado, las motivaciones tienen un peso importante frente a otras circunstancias que afectan al individuo en su tendencia a tomar vacaciones; sin embargo, no en la decisión para ir a un destino de vacaciones en particular donde influyen además otros factores. Como se ha reiterado, la imagen de un destino es el resultado de la percepción y la actitud del cliente hacia un destino turístico específico que da lugar a la elección de un destino en particular. 


\section{La percepción y las actitudes en el proceso de elección de un destino turístico}

Se puede identificar la percepción con los conocimientos que generan una determinada actitud que influye en el comportamiento en general del individuo $y$, por supuesto, en el comportamiento de compra. En el campo del turismo, la investigación científica con respecto a la percepción ha puesto el énfasis en la relación imagen-destino como factor determinante de los procesos de decisión. El análisis de dos aspectos importantes en este sentido: el rol de la percepción en los modelos de comportamiento del turista y la evidencia empírica de la importancia de la percepción como factor determinante de la imagen de destinos turísticos, demuestra que la percepción es un factor determinante de los mecanismos responsables de la creación de imágenes ligadas a los sitios turísticos considerados de forma previa a la decisión de compra y en consecuencia en la determinación de la decisión de viajar a un destino turístico.

Según Sönmez y Graefe (1998), entre otros autores, las actitudes de los clientes hacia los productos-servicios determinan su comportamiento; por tanto, la actitud es la predisposición a manifestar un comportamiento favorable o desfavorable respecto a algo concreto y puede no tener una base real. La actitud es una tendencia hacia algo y está marcada por las percepciones recibidas. El papel de las actitudes dentro del proceso de elección de un destino turístico se demuestra a través del análisis de tres aspectos importantes en relación con la actitud y el proceso de elección de un destino turístico, a saber: a) los conjuntos de elección del turista;b) las preferencias y el carácter dinámico de los conjuntos de elección del turista; y c) la evaluación de los conjuntos de elección por parte del turista potencial.

\section{La estructura del proceso decisional en los modelos de comportamiento del turista}

En el campo del turismo los modelos de comportamiento otorgan mucha importancia al proceso de la toma de decisión de compra. Por consiguiente, toda 
tentativa por comprender los mecanismos explicativos de comportamiento de viajeros debe, según nuestra opinión, concentrarse sobre el análisis de la "configuración lógica" del proceso decisional en cada uno de los modelos explicativos de comportamiento del turista.

Cuando se habla de configuración lógica de los procesos de decisión, se hace alusión a la naturaleza secuencial y ordenada de acciones o de nociones (aspectos) directamente o indirectamente relacionadas que actúan de manera sinérgica en aras de alcanzar un objetivo común; en este caso, la elección de un destino turístico determinado.A la luz de este conjunto de nociones es que fue analizado el proceso de elección de destinos de cada uno de los modelos de comportamiento del turista tomados en cuenta: a) el modelo de Schmoll (1977); b) el modelo de Mathieson y Wall (1982); c) el modelo de Moutinho (I987); d) el modelo de Woodside y Lysonski ( 1989); e) el modelo de Um y Crompton (1990); f) el modelo de Goodall (1992); g) el modelo de Mansfeld (1992); y h) el modelo de Sönmez y Graefe (1998).

En síntesis, se concluye que en la estructura de los modelos de comportamiento del consumidor, en el campo del turismo se puede distinguir cómo la motivación, las percepciones y las actitudes, dan lugar a determinados mecanismos de decisión que concluyen con la elección de un destino turístico; lo que demuestra el papel determinante de la imagen en dicho proceso de decisión. Además, analizadas las estructuras y límites descriptivos, según el criterio del proceso decisional de los modelos estudiados, es que se propone un modelo de elección de destinos turísticos que retiene los aspectos conceptuales y metodológicos desarrollados en este estudio.

\section{Un modelo de elección de destinos turísticos}

Después del análisis precedente, hay que reconocer que las relaciones percepción-preferencia-actitud (en su conjunto e interacción y lógica secuencial), no son consideradas de manera clara en la estructura de la mayoría de los modelos descriptivos del comportamiento del turista. Por otra parte, los modelos que otorgan más importancia a la percepción consideran que ésta es producto de efectos relativamente estables durante un cierto periodo de tiempo. Por otro lado, en cuanto al "proceso de elección" de un destino turístico, se ha establecido que la imagen (percepción-actitud) ocupa la posición central 
en todos los modelos analizados que en ocasiones se asemejan a cadenas secuenciales no completamente reconocibles, como en el caso del modelo de Mathieson y Wall (1982) y el de Moutinho (1987).

A fin de cuentas, si se considera el papel medular que juega la percepciónactitud en el contexto de los modelos de comportamiento del turista, se considera pertinente tratar de conceptualizar la secuencia de hechos-aspectos que llevan a cabo los turistas cuando deben tomar la decisión de elegir un lugar como destino de vacaciones.A estos efectos, se propone un modelo que integra todo el cuerpo teórico expuesto; que de forma clara deje constancia de la importancia de la percepción y actitud del potencial turista en la toma de la decisión final de compra, el carácter dinámico de los mecanismos ligados a la percepción, un adecuado mecanismo de retroactivación y, en general, todos los aspectos y variables que ayudarán a comprender el comportamiento de compra del turista.

El modelo tiende a describir la secuencia decisional del turista a partir de la integración conceptual de las principales nociones que se consideran fundamentales en la comprensión del comportamiento del viajero. En efecto, el diseño conceptual del modelo que se propone descansa en las nociones referentes a los conjuntos de clasificaciones de los productos; así como, en los conceptos de conjunto posterior, conjunto de acción, conjunto de reposo $y$, finalmente, conjunto de interacción. De esta forma, en una conceptualización global, el modelo reúne los aspectos antes mencionados, integrándolos bajo la forma de una cadena secuencial, que comienza con la formación de percepciones-actitudes (imágenes) asociadas a los sitios turísticos y termina con la elección de un destino en particular (véase figura I).

En cuanto a su configuración estructural, el modelo de comportamiento del turista incluye tres partes esenciales; éstas son: I) el proceso de percepción-preferenciaactitud (imagen); 2) el proceso de elección del destino; y 3) factores influyentes.

El proceso de percepción-preferencia-actitud, muestra de manera esquemática, la forma en la cual los atributos/características de los destinos turísticos, los factores del entorno y personales, los prejuicios y estereotipos del individuo y la experiencia vacacional, forman la naturaleza de los deseos, motivos, percepciones, preferencias y actitudes en general (imagen) que permiten al turista crear su conjunto preliminar de elección de destinos. Así, los factores que "caracterizan al individuo" tales como las variables culturales, 


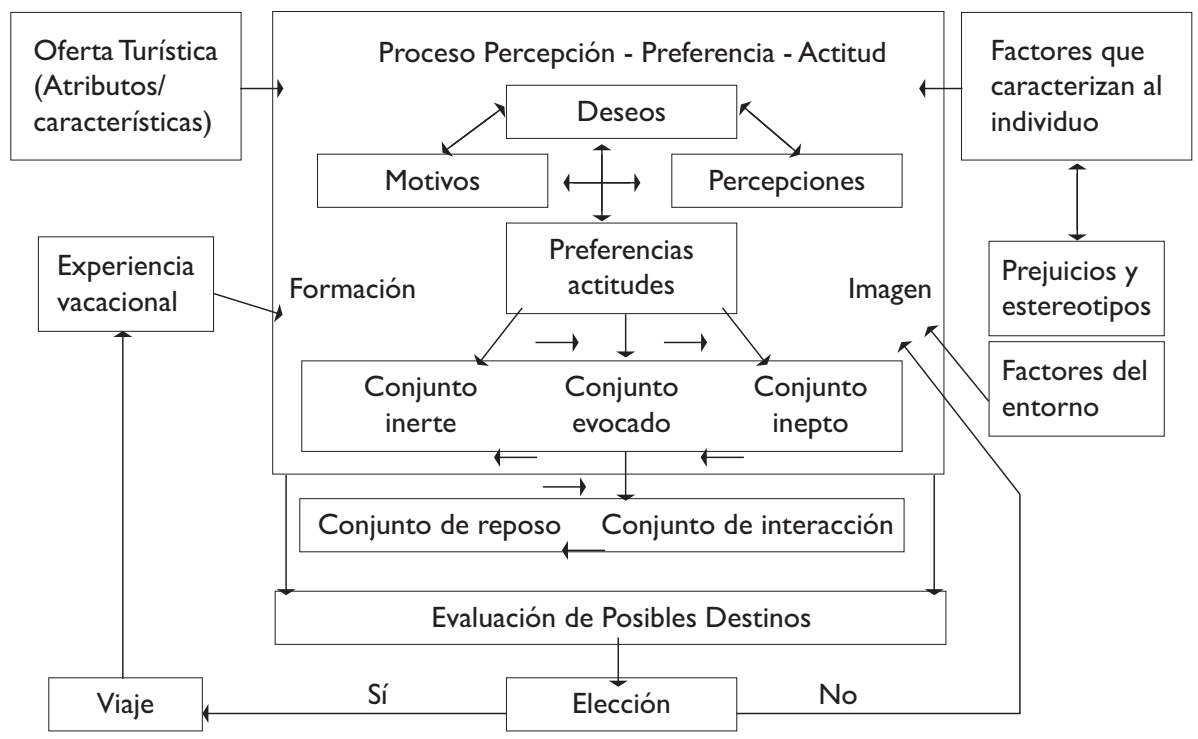

Figura I. Modelo de elección de Un destino turístico Fuente: Elaboración propia.

sociales y demográficas, los factores del entorno (económicos, políticos, socioculturales y tecnológicos; los atributos de los destinos turísticos y la experiencia vacacional del turista, estimulan simultáneamente la dimensión sensorial del individuo que por medio de mecanismos de percepción selectiva desarrolla y fortalece los deseos, identifica los motivos de viaje, asocia las imágenes positivas o negativas a los destinos turísticos y forma las preferenciasactitudes concretas hacia un cierto número de destinos a considerar en su conjunto preliminar de elección de destino turístico. De hecho en el modelo, los deseos, los motivos, las percepciones, las preferencias y las actitudes (imagen) del viajero son presentados como una red interactiva, en la cual, los componentes mantienen una relación de influencia recíproca.

En este orden de ideas el modelo sugiere que gracias a los efectos de la interacción dinámica y la sinergia resultante de los deseos, motivos, percepciones, preferencias y actitudes en la mente del turista, éste llega a identificar un cierto número de lugares de ocio, siendo un proceso mental difícil de separar dado el conjunto global de mecanismos cognitivos e interpretativos del turista. La 
formación del conjunto preliminar no se representa de forma explícita en el diseño estructural del modelo, ya que en lugar de representar este conjunto en sí, el modelo muestra más bien los resultados concretos de este proceso.Así, el modelo propone que los efectos resultantes de la interacción sinérgica de los deseos, los motivos, las percepciones, las preferencias y las actitudes (imagen en general) formadas por medio de los procesos selectivos de la percepción dan lugar en un primer momento a la formación del conjunto preliminar del turista; después (podría ser casi de forma simultánea) a la formación del conjunto evocado, el conjunto inerte y el conjunto inepto (véase figura I), a partir de los cuales se lleva a cabo el proceso de elección de un destino turístico.

En la perspectiva del modelo, el proceso de elección de destino turístico constituye una cadena de estructura causal simple, integrada por el conjunto de acción, la evaluación de lugares de ocio y la elección del destino.Además, se establece que el conjunto de acción puede dividirse en conjunto de interacción (interaction set) y el conjunto de reposo (quiet set). El conjunto de interacción contiene los destinos a propósito de los cuales el turista pedirá información específica en las agencias de viajes, oficinas de turismo, etc. Por otra parte, el conjunto de reposo, está integrado por los destinos retenidos en la memoria del viajero, pero no serán objetivo de viaje o búsqueda de información por el momento.

Las preferencias del turista por los sitios de ocio de su conjunto inicial de interacción, no asegura jamás que uno de esos sitios sea finalmente elegido como destino de viaje. Por ello, el modelo considera que los conjuntos de interacción y reposo no son una clasificación estática sino dinámica; por esto siempre puede darse una variación entre sus respectivos destinos que los componen. Es decir, los componentes del conjunto de interacción pueden volverse componentes del de reposo y viceversa, por medio de mecanismos de retroactivación del individuo. Dado el carácter dinámico de los conjuntos de interacción y de reposo, el modelo postula que el turista elige un destino de viaje a partir de aquellos que forman su conjunto de interacción en el momento de su elección. Es a partir de su último conjunto de interacción que el turista potencial hará la evaluación final de los destinos retenidos el cual puede acabar con la elección de un destino o, en todo caso, repetir todo el proceso, regresando al proceso inicial de percepciones-preferencias-actitud por medio de mecanismos de retroactivación. 


\section{Conclusiones}

En cuanto a la configuración global del modelo se puede decir en términos generales, que adopta la forma de una cadena causal simple, en la cual el proceso de percepción-actitud precede al proceso de elección del destino.Así, el conjunto evocado como componente principal del conjunto preliminar da origen al conjunto de acción que es el primer eslabón del proceso decisional del modelo.

Ha quedado claro cómo la imagen (percepción-actitud) da lugar a determinados mecanismos de decisión que desembocan en la elección de un destino turístico en todos los modelos de comportamiento del consumidor en el sector turístico estudiados, aunque en algunos de ellos no aparezca de forma explícita en la estructura secuencial que conduce a la elección del destino, como se ha analizado.También, en el modelo propuesto de elección de un destino turístico por parte del consumidor, la imagen (percepción-actitud) es el elemento fundamental y determinante en la formación de los diferentes conjuntos de elección, a partir de los cuales se realiza la elección definitiva. De hecho, partiendo de los deseos, las motivaciones iniciales, percepciones, preferencias, actitudes en general, se seleccionan los destinos que forman parte del conjunto preliminar y se comienza la evaluación de las alternativas de viaje consideradas sobre la base del concepto de "utilidad", la evaluación destinos atributos, y la vía o forma en que se utiliza la información disponible para efectuar dicha evaluación. Por tanto, una escala de percepción-preferencia, junto a un criterio de decisión, es la base del proceso de selección de las alternativas de viaje y la elección final. Por ello la importancia del estudio de técnicas de medición de la imagen (percepciones y actitudes) y el posicionamiento de un destino turístico, de forma tal que permita analizar los procesos, limitaciones y aciertos en relación con esta problemática.

\section{FUENTES CONSULTADAS}

Baker, D.y Crompton,J. (2000)."Quality, satisfaction and behavioral intentions”. Annals of Tourism Research, 27, 3, 785-804.

Baloglu, S. y McCleary, K. (1999). “A model of destination image formation”. Annals of Tourism Research, 26, I, 868-897. 
Botha, C., Crompton, J. y Kim, S. (1999). "Developing a revised competitive position for sun/Lost City, South Africa". Journal of Travel Research, $37,34 \mid-352$.

Engel, J. Kollat y Blackwell, R. (1968). Consumer Behavior, Nueva York: Holt, Rinehart and Winston.

Engel, J. Blackwell, R. y Miniard, P. (1986). Consumer behavior. Chicago: The Dryden Press.

Goodall, B.(1992).“How tourists choose their holidays:An analytical framework”, en B. Goodall y G.Ashworch (eds.). Marketing in the tourism industry.The promotion of destination region, Londres: Croom Helm, I - I0.

Holloway y Robinson (1995). Marketing forTourism. $3^{\text {a }}$ ed., Reino Unido:Adisson Wesley Longman.

Howard, J.y Sheth, J. (1969). The theory of buyer behavior. New York: John Wiley. Kotler, P. (1983). Principles of Marketing. $2^{\mathrm{a}}$ ed., Englewoods Cliffs: Prentice- Hall. (1997). Marketing management: Analysis, planning and control. London: Prentice-Hall International.

Lumsdom, L. ( 1997). Marketing for tourism. Reino Unido: International Thompson Press.

Mansfeld, Y. (1992). "From Motivation to Actual Travel”, Annals of Tourism Research, 19, 399-419.

Maslow, A. (1970). Personality and motivation. New York: Marper and Row.

Mathieson, A. y Wall, G. (I 982). Tourism: Economic, physic and social impacts. London: Longman Group Limited.

Middleton, V. (1988). "Marketing in travel and tourism”. Marketing countries as tourism destination. Oxford: Heinemann Professional Publishing. 209-225.

(1995). “Overall tourism product”, en Witt, S. y Moutinho, L. (eds.). Tourism marketing and management handbook. Londres: Prentice Hall International.

Mill, R.y Morrison,A. ( 1985$)$. The tourism system:An introductory text. New Jersey: Prentice- Hall International Inc.

Moutinho (1987). "Consumer behavior in tourism”, European Journal of Marketing, 2 I, núm. 10, 5-44.

Murphy, P., Pritchard, M. y Smith, B. (2000). "The destination product and its impact on traveler perceptions". Tourism Management, 2I, 43-52. 
Nicosia, F. (1966). Consumer decision process: Marketing and Advertising implications. New Jersey: Prentice- Hall International Inc.

Pearce, D. (2000). "Tourism plan reviews. Methodological considerations and issues from Samoa”. Tourism Management, 21, I9I-203.

Schmoll, G. (1977). Tourism promotion. Londres:Tourism International Press.

Sessa, A. ( 1 989) “Caracteristics of tourism” en Witt, S. F. y Moutinho, L. (eds.). Tourism marketing and management handbook. Cambridge: Prentice Hall International, University Press, 43 -45.

Sönmez,S.F.y Graefe, a. R.( 1998).“Influence of terrorism risk on foreign tourism decisions”, Annals of Tourism Research, 25, I, I I2-I 45.

Um, S. y Crompton, J. L. (1990). “Attitude determinants in tourism destination choice", Annals of Tourism Research, 17, 432-448.

Uysal, M., Chen, J. S. and Williams, D. R. (2000) "Increasing State Market Share Through a Regional Positioning”, Tourism Management 2I, I, 89-96.

Woodside,A. G. y Lysonski, S. ( 1989). “A general model of traveler destination choice”. Journal of Travel Research, 27, 4, 8-I4 